\title{
Traction-assisted endoscopic submucosal dissection for a gastric lesion involving the pyloric ring and duodenal bulb
}

An 81-year-old woman underwent an upper gastrointestinal endoscopy because of anemia. Two lesions were detected: a 30-mm type 0-Ip located in the lesser curvature of the antrum, and a $25-\mathrm{mm}$ type 0 -Is involving the upper hemisphere of the pylorus and the proximal duodenal bulb. Biopsy specimens revealed hyperplastic polyp and adenocarcinoma, respectively. Endoscopic submucosal dissection (ESD) was proposed ( $\vee$ Video 1 ). The procedure was performed using an insulated-tipped knife (IT-knife 2; Olympus, Tokyo, Japan), with the patient under deep sedation. First, a submucosal injection on the distal part was performed and initial approach to the lesion from the duodenal bulb was attempted; however, neither the forward nor retroflexion view allowed a good endoscopic approach to the lesion. Therefore, clip traction was performed using dental floss, pulling the whole lesion into the gastric lumen ( $\triangleright$ Fig. 1). ESD was accomplished from the distal to the proximal side ( $>$ Fig. 2 ), achieving en bloc resection of both lesions on the same pathological specimen ( $\triangleright$ Fig. 3 ). At the end of
ESD, moderate bleeding was observed from two vessels in the scar, and five hemoclips were applied for successful hemostasis ( $>$ Fig.4). Major nonbleeding vessels were coagulated using Coagrasper Hemostatic Forceps (Olympus) to prevent delayed hemorrhage. The procedure time was 60 minutes. The patient did not develop complications and was discharged after 3 days.

Histopathological examination revealed a hyperplastic polyp without dysplasia in the $30-\mathrm{mm}$ lesion, and a moderately differentiated intramucosal adenocarcinoma, without lymphovascular invasion and with negative horizontal margins in the 25-mm lesion (expanded curative criteria).

The pylorus and duodenal bulb have been reported among the most challenging locations for performing ESD, with a greater risk of complications [1-3]. The complete resection rate decreases for tumors that are located in the upper hemisphere, have duodenal extension, and have a large circumferential extent of resection [3]. Different traction systems have been developed to assist ESD.

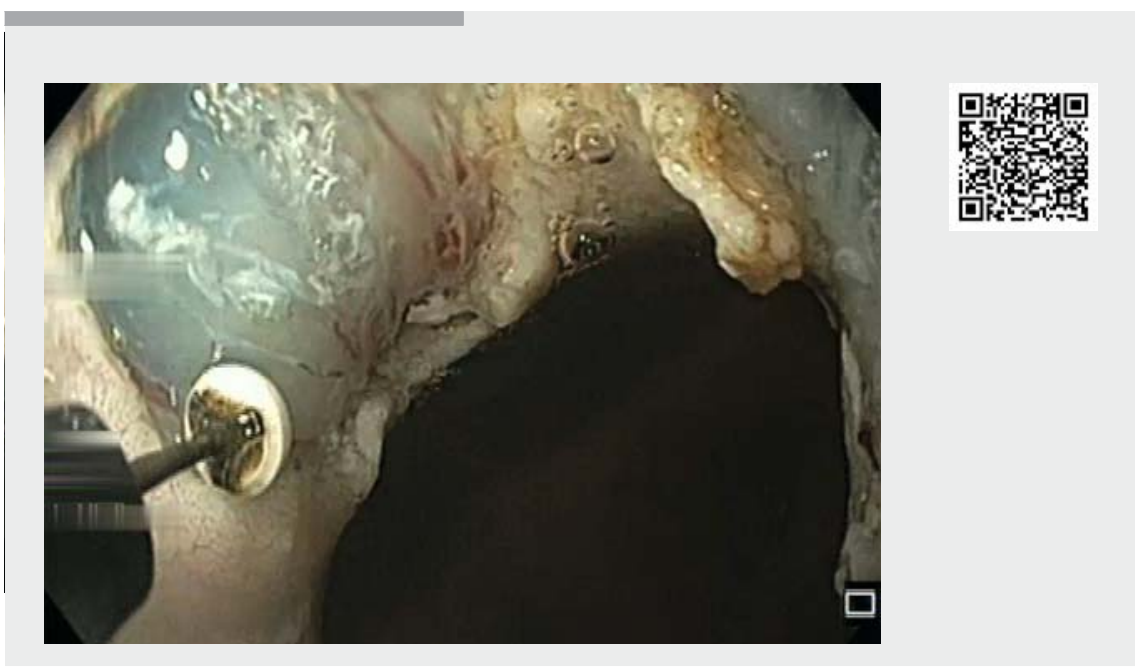

$\checkmark$ Video 1 Traction-assisted endoscopic submucosal dissection for a gastric lesion involving the pyloric ring and duodenal bulb.

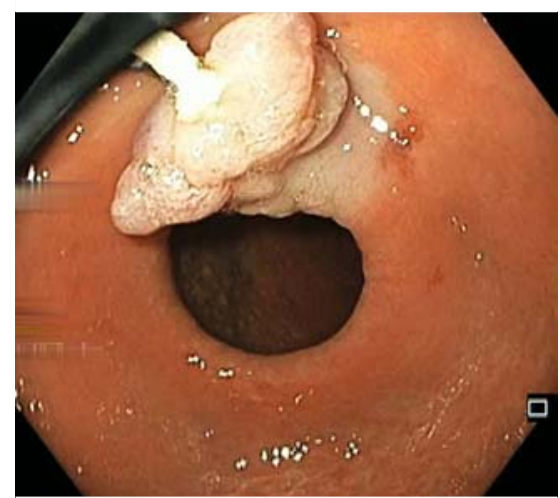

Fig. 1 Traction with dental floss and clip was performed from the duodenal part of the lesion.

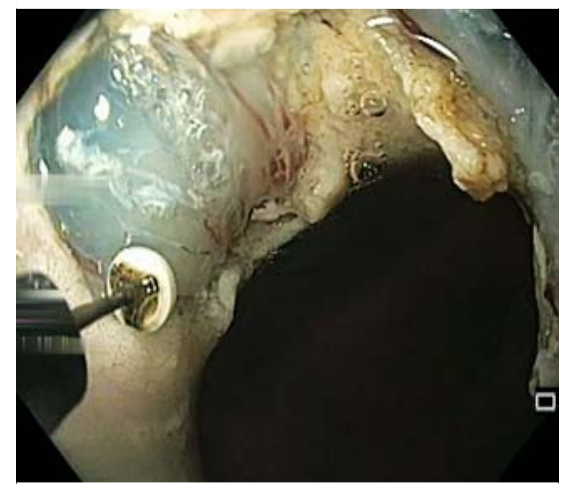

- Fig. 2 Endoscopic submucosal dissection was performed from the distal to the proximal side.

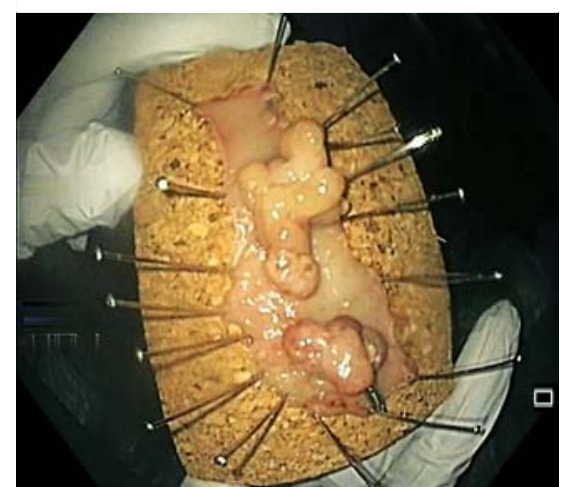

- Fig. 3 En bloc resection was achieved for both lesions in the same pathological specimen. 


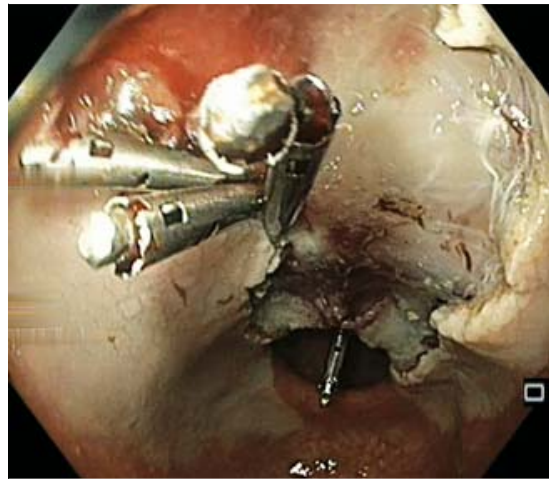

- Fig. 4 After completing the resection, moderate bleeding was observed from two vessels in the scar, and five hemoclips were applied.

Among them, dental floss and clip traction is a simple, feasible, and cost-effective method that allows the procedure time to be shortened while achieving en bloc resection $[4,5]$.

Endoscopy_UCTN_Code_TTT_1AO_2AN

Competing interests

None

The authors

Marta Rodríguez-Carrasco ${ }^{1}$, Gonçalo Nunes ${ }^{2}$, Diogo Libânio ${ }^{1,3}$, Pedro Pimentel-Nunes ${ }^{1,3,4}$, Mário Dinis-Ribeiro ${ }^{1,3}$

1 Gastroenterology Department, Portuguese Oncology Institute of Porto, Porto, Portugal

2 Gastroenterology Department, Hospital Garcia de Orta, Almada, Portugal
3 MEDCIDS - Department of Community Medicine, Information and Decision in Health, Faculty of Porto, University of Medicine, Porto, Portugal

4 Surgery and Physiology Department, Faculty of Medicine of the University of Porto, Porto, Portugal

\section{Corresponding author}

\section{Marta Rodríguez-Carrasco, MD}

Gastroenterology Department, Portuguese Oncology Institute of Porto, Rua Dr. Bernardino de Almeida, 4200-072 Porto, Portugal

Fax: +351-22-5513646

martarc7@gmail.com

\section{References}

[1] Imagawa A, Okada H, Kawahara Y et al. Endoscopic submucosal dissection for early gastric cancer: results and degrees of technical difficulty as well as success. Endoscopy 2006; 38: 987 - 990

[2] Lim CH, Park JM, Park CH et al. Endoscopic submucosal dissection of gastric neoplasia involving the pyloric channel by retroflexion in the duodenum. Dig Dis Sci 2012; 57: $148-154$

[3] Bae JH, Kim GH, Lee BE et al. Factors associated with the outcomes of endoscopic submucosal dissection in pyloric neoplasms. Gastrointest Endosc 2015; 81: $303-311$

[4] Koike Y, Hirasawa D, Fujita $N$ et al. Usefulness of the thread-traction method in esophageal endoscopic submucosal dissection: randomized controlled trial. Dig Endosc 2015; 27: $303-309$

[5] Jeon W], You IY, Chae HB et al. A new technique for gastric endoscopic submucosal dissection: peroral traction-assisted endoscopic submucosal dissection. Gastrointest Endosc 2009; 69: 29-33

\section{Bibliography}

DOI https://doi.org/10.1055/a-1011-3769

Published online: 27.9.2019

Endoscopy 2020; 52: E96-E97

(c) Georg Thieme Verlag KG

Stuttgart · New York

ISSN 0013-726X

\section{ENDOSCOPY E-VIDEOS}

https://eref.thieme.de/e-videos

回故 Endoscopy E-Videos is a free 留 靣嵃: on interesting cases and new techniques in gastroenterological endoscopy. All papers include a high quality video and all contributions are freely accessible online.

This section has its own submission website at https://mc.manuscriptcentral.com/e-videos 